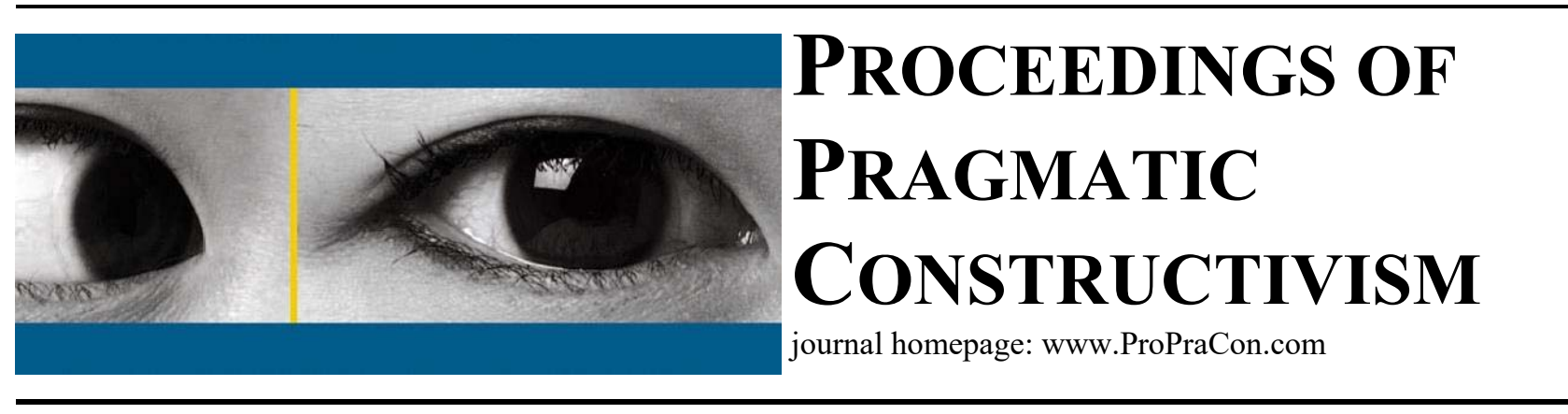

\title{
Editorial: Seeing beyond social "bubbles" by the help of pragmatic constructivism
}

\author{
Morten Jakobsen, \\ Department of Management, Aarhus University \\ Email: mja@mgmt.au.dk \\ Tuomas Korhonen \\ Cost Management Center at the Tampere University \\ Email: tuomas.korhonen@tuni.fi \\ Teemu Laine, \\ Cost Management Center at the Tampere University \\ Email: teemu.laine@tuni.fi
}

\section{Pragmatic constructivism could facilitate seeing beyond social "bubbles"}

Pragmatic constructivist (PC) studies are about making difference in organizations (Jakobsen et al. 2017; Norreklit, 2017), and at the same time PC enables acknowledging the different human actors within those organizations in a holistic way. This fundamental basis will not change even if new technologies and digital procedures change the everyday life of the organizations, and enables new ways to identify, examine and realize factual possibilities.

PC research responds to the need of thoroughly understanding actors in different roles within organizations, which is evident in different streams of literature. In the literature on management accounting as a practice (Ahrens \& Chapman, 2007), it is acknowledged that the actors involved in an organization constitute the practice, and thus each action and interaction shapes the reality within the organization. Also, in the contingency theory-driven management accounting literature (Gerdin et al. 2014), it is brought up that management accounting is not only to report but also to reshape and direct the reality of an organization. In pragmatic constructivism, with an emphasis on a functioning practice, it is quite natural that the value-driven selection of facts and the recognition of possibilities (Laine et al. 2016) have a remarkable effect on the constituents of the reality and perhaps more importantly, on the process through which the reality is continuously (re-)constructed.

The role of actors, as noted, and also the role of the process of communication and interaction among actors in (re)constructing the functioning practice will remain extremely important when new technological tools have become available. Indeed, one may argue that awareness of the process of selecting facts and recognizing and acting upon the possibilities is more important than ever before.

In the social media, for example, our acts and activities continuously reshape the reality that is made visible to us. We choose to watch videos, to react or not to react to certain inputs, or to send messages to different actors. As a result, the reality around us is continuously reconstructed by our actions, other actors' actions and the choice of facts that are considered important by the technological tools and the embedded algorithms. While it is rather efficient that the technological tools make those facts visible and surface possibilities that seem to fit our previous activities, we have to be careful in our reflections that those facts are not illusions. It would be tempting to choose facts that fit our preunderstanding, but still (or therefore) it would be extremely important to continuously reflect on the reality around us, and examine, whether the facts and possibilities indeed are factual. 
It might be valuable to reflect upon our de facto reality in the social media that reflects our choices, reactions and other actors that are active around us. Such reality may better or worse correspond to our values translated into our actions. Perhaps, interesting difference may appear between our stated values and taken actions in social media and outside those technological tools. Another consequence of our choices that reflect our values and preferences is the fact that other actors around us seem to share similar sets of values. Thus, we may create a "bubble" where certain values, facts, and preferences about possibilities are shared, and thus considered as the (only) correct ones.

For pragmatic constructivism, it is a highly relevant, yet challenging task to examine these "bubbles" as constructed topoi within the social media, within other technological tools and also in real life. It is, of course, highly important to communicate within our closer groups such as with our friends and close colleagues. However, PC could be employed to unveil different facts and illusions across different social "bubbles" and to help overcoming different challenges emerging from misunderstandings within and across those "bubbles". Despite the fact that social media and technological tools may be rather effective and efficient in many ways to foster communication and enhance organizational practices, PC could remain as an approach that serves as a critique that unveils hidden values, misunderstanding and other shortcomings in communication - and the organizational practices more broadly.

\section{About this issue}

In order for PC to succeed in the agenda outlined above, it needs to be continuously developed and examined as an approach. We are happy to report such advancements also within this issue of the Proceeding of Pragmatic Constructivism. Indeed, the issue covers a wide range of theoretically interesting insights related to PC. To us, the four papers of the issue look at the development of PC particularly from equally interesting viewpoints. The paper by Janne Mämmelä et al. (2019) examines the types of communication in product development. The paper by Thomas Bolander (2019) addresses the differences between human and artificial intelligence (AI). The papers by Lars Bo Henriksen (2019) and Morten Jakobsen (2019) address openness and mutual respect as important methodological concerns.

One way to engage in topical academic debates in the area of PC are applications of the approach in other fields. This is what Janne Mämmelä et al. (2019) attempt. In their paper, "Communicating design knowledge to support technology management in the manufacturing industry: an application of pragmatic constructivism”, Mämmelä et al. bridge design research with PC. Communication is extremely important in this bridge construction: while designing e.g., pieces of equipment is largely a technical exercise, it also needs to be socially organized. Consequently, Mämmelä et al. attempt to advance PC particularly in the area of communication. Especially, Mämmelä et al. work on types of communication in the product development context found in prior pragmatic constructivist literature (i.e., co-authorship, knowledge integration; boundary subject and communication hubs; communicative probes; modes of communication; and communication as a vehicle for verification), adding to topical discussions in the research field by both substantiating earlier findings and elaborating on them.

In his paper, "Human vs machine intelligence: How they differ and what this implies for our future society", Thomas Bolander (2019) makes a very thorough account on what the distinction of human intelligence vs. AI is. In his paper, Bolander shows that AI is not capable of similar intelligence than humans (at least not at the moment), which necessitates collaboration between AI and human actors. Thus, ultimately, utilizing AI is a social endeavour. Regarding such social endeavours, Bolander stresses the aspects of trust and explainability. Trust and explainability are central in any interaction, and interacting with AI is not different in that sense. Although Bolander's paper is primarily an introduction to AI (currently) for researchers outside the field of AI, the paper also offers many leads for us pragmatic constructivists. Linguistics and social intelligence are difficult for machines whereas for us humans they are natural parts of our life. Similarly, building trust in AI is a human problem. Future research could answer questions such as how organizations could (not) build trust on AI as a problem-solving tool - if AI lacks explainability, as Bolander presents. Which kinds of language games are used for this trust building? Furthermore, which kinds of possibilities do managers see for $\mathrm{AI}$ in the field of management?

In his paper, "Language Games, Dialogue and the Other", Lars Bo Henriksen (2019) examines a very fundamental question, that is: how can we study processes that we ourselves are parts of? Henriksen reminds us that we should avoid confirming our own prejudices when observing practice (e.g., when interviewing practitioners), but rather, to maintain adequate 'openness' to phenomena observed and narratives examined. With language games being one of the central concepts in many current pragmatic constructivist debates, Henriksen's paper is a welcome and topical contribution. Indeed, we wish that the Proceedings of Pragmatic Constructivism would be an increasingly relevant home for such theoretical debates that concern us as researchers. With papers that are useful for a wide range of researchers, we believe the Proceedings of Pragmatic Constructivism could increasingly have an impact on the academic community by elaborating widely relevant concepts and offering food for pragmatic constructivist thought.

Finally, Jakobsen (2019) addresses another very important methodological aspect for PC, in his article "Helping as the topoi for interventionist research from a pragmatic constructivist point of view". Indeed, Jakobsen notices that particularly in interventionist research, it is highly important to acquire an atmosphere of mutual respect. By drawing 
from Søren Kierkegaard's work, Jakobsen suggests that if the researcher and the practitioner are able to really understand each other, they can help each other pursue their (common or) separate goals.

Altogether, the issue deals with developing and discussing PC as an approach as well as using the PC approach within the organizational practices. Importantly, in many PC studies, also the researcher is considered as an actor, who may be a rather important part of both understanding the organizational practice and thus developing it. Studies on interventionist approaches (Lyly-Yrjänäinen et al. 2017) and related considerations place an emphasis on actors helping each other and eventually paving the way towards developing a functioning practice. However, neither PC researchers nor interventionist researchers are "better" in developing functioning practices, but these approaches enable and encourage openness for critical reflections regarding fact construction, the identification of possibilities and their examination. Therefore, we encourage PC researchers to actively engage with timely debates and organizational practices, to the benefit of the management scholar community.

\section{References:}

Ahrens, T., \& Chapman, C. S. (2007). Management accounting as practice. Accounting, organizations and society, 32(12), 1-27.

Bolander, T. (2019). Human vs machine intelligence: How they differ and what this implies for our future society. Proceedings of Pragmatic Constructivism (this issue).

Gerdin, J., Messner, M., \& Mouritsen, J. (2014). On the significance of accounting for managerial work. Scandinavian Journal of Management, 4(30), 389-394.

Henriksen, L. B. (2019). Language Games, Dialogue and the Other. Proceedings of Pragmatic Constructivism (this issue).

Jakobsen, M. (2019). Helping as the topoi for interventionist research from a pragmatic constructivist point of view. Proceedings of Pragmatic Constructivism (this issue).

Jakobsen, M., Korhonen, T., \& Laine, T. (2017). Pragmatic Constructivism for making a difference in organizations. Proceedings of Pragmatic Constructivism, 7(1), 3-3.

Laine, T., Korhonen, T., Suomala, P., \& Rantamaa, A. (2016). Boundary subjects and boundary objects in accounting fact construction and communication. Qualitative Research in Accounting \& Management, 13(3), 303-329.

Lyly-Yrjänäinen, J., Suomala, P., Laine, T., \& Mitchell, F. (2017). Interventionist management accounting research: Theory contributions with societal impact. Routledge.

Mämmelä, J., Korhonen, T., Juuti, T., \& Julkunen, P. (2019). Communicating design knowledge to support technology management in the manufacturing industry: an application of pragmatic constructivism. Proceedings of Pragmatic Constructivism (this issue).

Nørreklit, H. (Ed.). (2017). A philosophy of management accounting: A pragmatic constructivist approach. Taylor \& Francis. 